\title{
Pengaruh bone graft dan splitting osteotomy terhadap perkembangan akar gigi molar ketiga immature yang ditransplantasi The effect of bone graft and splitting osteotomy on development of the root of transplanted immature third molar
}

\author{
${ }^{1}$ Irma Drismayanti, ${ }^{1}$ Sariatun T, ${ }^{2}$ Surijana Mappangara, ${ }^{2}$ Muh. Ruslin \\ ${ }^{1}$ Mahasiswa tahapan profesi \\ ${ }^{2}$ Bagian Bedah Mulut dan Maksilofasial \\ Fakultas Kedokteran Gigi Universitas Hasanuddin \\ Makassar, Indonesia
}

\begin{abstract}
One of the basic requirements for succesfull transplantation is an adequate size of recipient site with sufficient alveolar support. If the transplantation is performed into a fresh extraction site, the recipient site can easily be adjusted to the transplantation. However, the situation is different in patient with premolar aplasia or early molar loss with marked atrophy of the alveolar process, need additional surgical procedures like bone autograft or splitting osteotomy of the alveolar process. This paper discussed the effect of bone autograft and splitting osteotomy on root development of transplanted immature third molars. The conclusion is these additional surgical prosedures had a negative effect on the pulpal and periodontal condition of transplantated immature third molars. This may be related to revascularization disturbances of pulp due to nutrient insufficiency of the recipient site.
\end{abstract}

Key word: tooth transplantation, bone graft, splitting osteotomy

\begin{abstract}
ABSTRAK
Syarat dasar untuk berhasilnya transplantasi adalah ukuran daerah resipien yang adekuat dengan dukungan prosesus alveolaris yang memadai. Jika transplantasi langsung dilakukan ke dalam ruang bekas pencabutan gigi, daerah resipien dapat dengan mudah menerima transplantasi. Akan tetapi situasi ini berbeda pada pasien dengan aplasia premolar atau kehilangan dini gigi molar yang ditandai dengan atrofi prosesus alveolaris yang membutuhkan prosedur bedah tambahan direkomendasikan untuk memperoleh daerah resipien yang adekuat seperti bone autograft atau splitting osteotomy prosesus alveolaris. Makalah ini membahas tentang pengaruh bone autograft dan splitting osteotomy terhadap perkembangan akar gigi molar ketiga immature yang ditransplantasi. Sebagai simpulan, splitting osteotomy diketahui memiliki efek negatif terhadap pulpa dan kondisi jaringan periodontal pada gigi molar ketiga immature yang ditransplantasi. Hal ini berhubungan dengan gangguan revaskulariasi pulpa yang disebabkan oleh ketidakcukupan nutrisi pada daerah resipien.
\end{abstract}

Kata kunci: transplantasi gigi, bone graft, splitting osteotomy

Koresponden: Irma Drismayanti, Mahasiswa tahapan profesi Fakultas Kedokteran Gigi Universitas Hasanuddin. Jl. Perintis Kemerdekaan Km.10, Makassar 90245, Indonesia. E-mail: neneg_dentist@yahoo.co.id.

\section{PENDAHULUAN}

Transplantasi molar ketiga yang belum terbentuk sempurna telah banyak diterima dan menjadi tindakan perawatan yang dapat diandalkan pada kasus kehilangan gigi dini atau aplasia. ${ }^{1}$ Transplantasi yang dilakukan ke daerah bekas pencabutan gigi yang masih baru memiliki tingkat keberhasilan yang lebih tinggi dibandingkan dengan tranplantasi pada daerah yang telah mengalami atrofi akibat kehilangan gigi yang sudah lama karena gigi yang ditransplantasi dapat beradaptasi dengan lebih mudah terhadap soket yang baru. ${ }^{1-2}$

Pada sebagian besar kasus dengan atrofi vertikal dari prosesus alveolaris digunakan free bone autograft dari angulus mandibula atau dari regio mentale. Dalam penelitian yang dilakukan oleh Oskar Bauss dkk., penatalaksanaan bone graft dipisahkan berdasarkan panjang ukuran yang diperlukan. Setelah transplantasi, bone graft kemudian ditempatkan dengan permukaan kortikal berbatasan dengan permukaan akar yang bertujuan untuk menutupi permukaan akar. Sedangkan pada kasus dengan atrofi horisontal dari prosesus alveolar digunakan splitting osteotomy untuk melebarkan daerah resipien. Pada tatalaksananya, setelah dilakukan insisi mukosa, plat kortikal bukal dipotong dengan satu osteotomy sagital dan dua osteotomy vertikal lalu sebuah chisel dimasukkan ke dalam dan ditekan ke daerah bukal sehingga terbentuk celah untuk menempatkan gigi yang akan ditransplantasi. ${ }^{1-2}$

Kedua prosedur bedah direkomendasikan untuk memperoleh daerah resipien yang adekuat 
pada transplantasi gigi ke daerah yang sudah mengalami atrofi guna memenuhi salah satu syarat dasar untuk keberhasilan transplantasi. Namun di sisi lain, kedua prosedur bedah tersebut juga dapat menjadi pencetus terjadinya gangguan vaskuler ke pulpa yang dapat menyebabkan kematian pada gigi yang ditransplantasi. Penulisan artikel ini bertujuan untuk membahas pengaruh prosedur bone autograft dan splitting osteotomy terhadap perkembangan akar gigi molar ketiga immature yang ditransplantasi dengan melihat panjang akhir akar gigi dan penambahan panjang akar gigi.

\section{TINJAUAN PUSTAKA}

\section{Tahap-tahap perkembangan akar gigi}

Setiap gigi berbeda-beda bentuknya secara anatomi, tetapi dasar proses pertumbuhannya sama. Setiap gigi tumbuh berturut-turut mulai dari tahap bud, cup, dan bell. Pada tahap bell dibentuk email dan dentin. Mahkota terbentuk dan termineralisasi, kemudian diikuti pembentukan akar gigi. Setelah kalsifikasi akar, jaringan pendukung gigi, sementum, ligamentum periodontal, serta tulang alveolar tumbuh. Pertumbuhan akar dan sementogenesis berlanjut sampai gigi berfungsi dan didukung oleh struktur gigi yang tumbuh sempurna. ${ }^{3}$
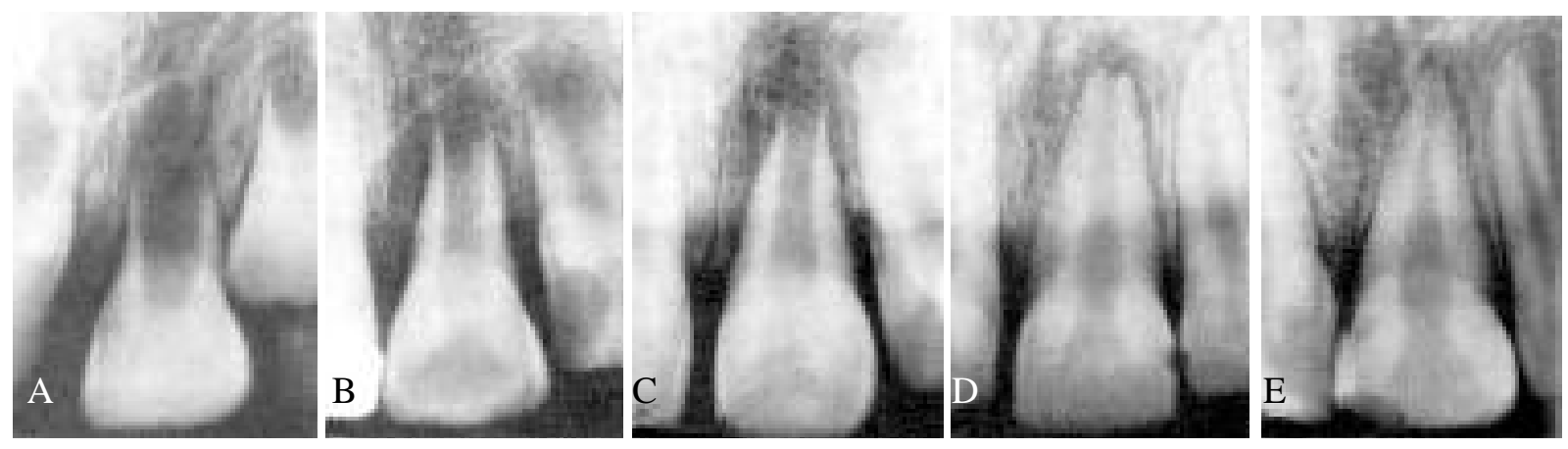

Gambar 1. Tahap-tahap perkembangan akar gigi: A. Tahap 1, B. Tahap 2, C. Tahap 3, D. Tahap 4. E. Tahap 5. (Sumber: Mathew BP, Hegde MN. Management of non vital immature teeth. Endodontology. [online] 2009 [cited 2009 December 19] Available from: http://medind.nic.in/eaa/t06/i1/eaat06i1p18.pdf).
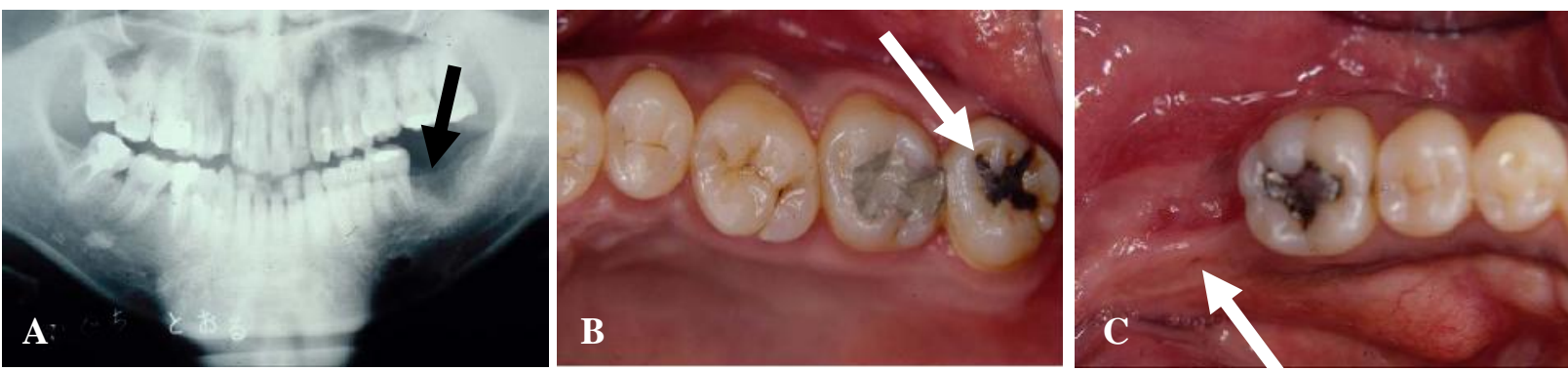

Gambar 2. A. Gambaran foto panoramik yang menunjukkan gigi molar ketiga RA yang akan ditransplantasi ke daerah edentulus molar kedua RB. B. Gigi molar ketiga RA yang akan ditransplantasi. C. Daerah edentulus molar kedua RB. (Sumber: Tanne K. Tooth transplantation: the current status and the future development with a cryopreservation technique for teeth banking The Medical Equipment Seminar between Switzerland and Japan; 2006 November 14; Zurich, Switzerland. Medical and Social Cooperating Center Graduate School of Biomedical Sciences Hiroshima University; 2006. p. 3-4) ${ }^{8}$ 

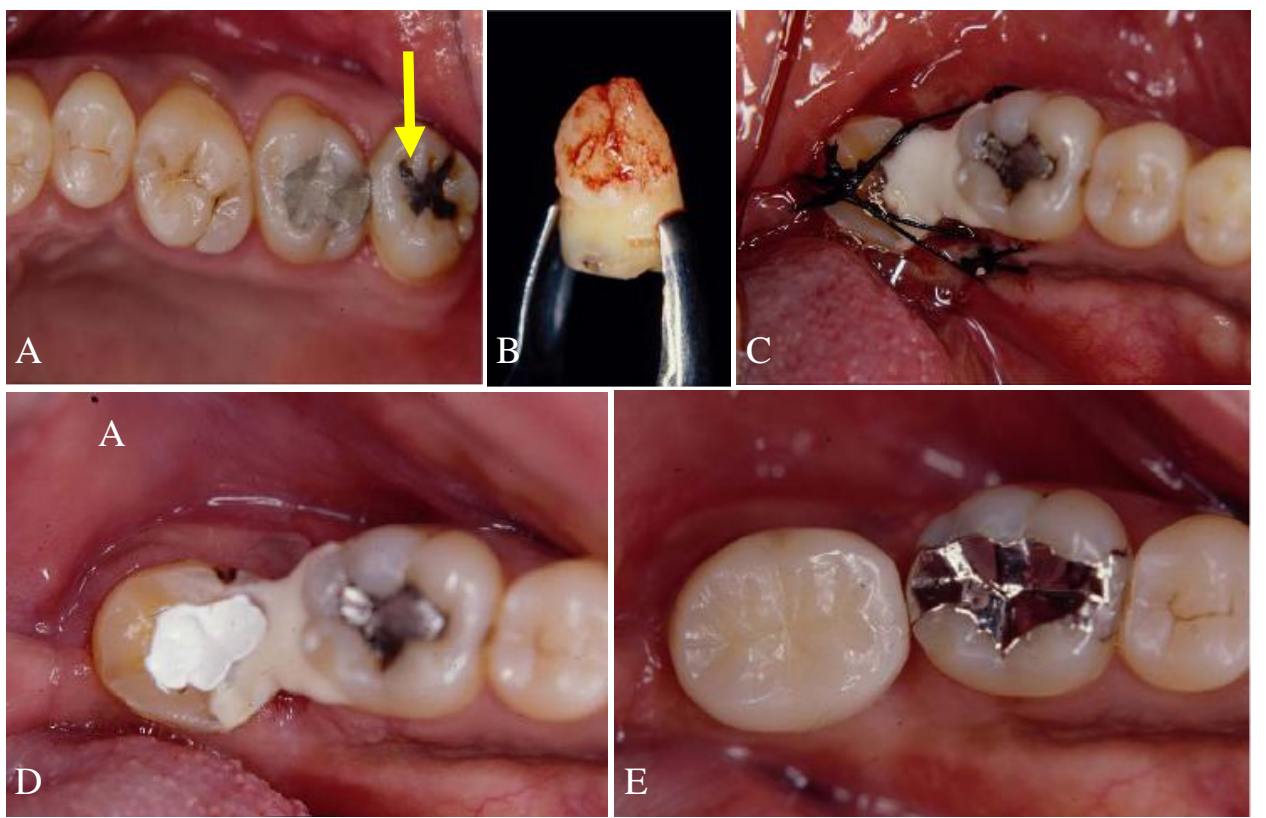

Gambar 3. Prosedur umum transplantasi gigi. A. Gigi molar ketiga RA yang akan ditransplantasi. B. Gigi dikeluarkan dari soket. C. Gigi transplantasi ditempatkan ke dalam soket molar kedua RB yang telah disiapkan kemudian difiksasi dengan jahitan splint menyilang di atas oklusal gigi. D. Penumpatan karies. E. Setelah transplantasi. (Sumber: Tanne K. Tooth transplantation: the current status and the future development with a cryopreservation technique for teeth banking. The Medical Equipment Seminar between Switzerland and Japan; November 14, 2006; Switzerland. Medical and Social Cooperating Center Graduate School of Biomedical Sciences Hiroshima Univ; 2006. p.3-4) ${ }^{8}$

\section{Transplantasi gigi}

Transplantasi adalah suatu tindakan memindahkan jaringan atau organ dari satu tempat ke tempat yang lain. Transplantasi autogenik atau autoplastik berarti donor dan resipien berasal dari individu yang sama (gambar 2 dan 3$)^{7}$

Transplatasi gigi merupakan penempatan gigi autogenous atau homolog ke dalam soket. Gigi mungkin suatu gigi yang sedang berkembang dari mulut yang sama, atau gigi vital atau non-vital atau gigi yang telah menjalani perawatan endodontik yang ditransplantasikan dari suatu tempat ke tempat lain pada individu yang sama atau dari satu individu ke individu yang lain. ${ }^{9}$

Indikasi transplantasi gigi adalah gigi yang impaksi atau gigi ektopik, premature loss, gigi yang hilang karena trauma, tumor, kongenital pada satu lengkung rahang dengan tanda klinis gigi yang berjejal pada lengkung rahang yang berlawanan, serta pada gigi dengan prognosis yang buruk. Kontra indikasi mencakup pasien dengan kelainan jantung, oral hygiene yang buruk serta motivasi yang rendah. ${ }^{10-11}$

Hal yang penting untuk berhasilnya suatu transplantasi adalah terjaganya vitalitas sel-sel periodonsium dan sementum gigi yang ditransplantasi. Jika serat periodontalnya masih vital, reorganisasi alami dari serat-serat periodontal dapat terjadi. Kontak yang minimal antar jaringan dengan daerah resipien dan permukaan akar gigi ketika gigi ditransplantasi ke daerah resipien yang telah disediakan sebelumnya, setelah transplantasi, hasilnya terjadi ketidakcukupan nutrisi pada sel-sel yang terdapat di permukaan akar yang menyebabkan kematian sel. Pada kasus ligamentum periodontal mengalami trauma selama transplantasi dapat menyebabkan resorbsi eksternal dan ankilosis. ${ }^{12}$ Trauma pada permukaan akar juga dapat mengganggu proses penyembuhan gigi yang ditransplantasi. Selain itu, suatu prasyarat dasar untuk keberhasilan transplantasi adalah ukuran daerah resipien yang adekuat dengan dukungan prosesus alveolar yang cukup untuk transplantasi. ${ }^{1}$

Pada awalnya gigi yang dipilih untuk transplantasi adalah gigi kaninus RA yang impkasi yang berperan penting dalam estetik dentofasial, kemudian berkembang pada gigi molar ketiga RB yang dapat ditransplantasi ke dalam soket gigi molar pertama RB. ${ }^{10}$ Pada penelitian yang dilakukan oleh Bauss, $\mathrm{dkk}^{1}$ gigi yang ditransplantasi adalah gigi molar ketiga yang belum terbentuk sempurna akarnya yang meliputi regio donor dan resipien berbeda dalam hal ini 
molar ketiga RA ditransplantasikan ke daerah molar RB.

Menurut Fong yang dikutip oleh Mendes dan Rocha, transplantasi gigi dengan pembentukan akar yang belum sempurna mempunyai rata-rata penyembuhan pulpa sekitar $96 \%$ dibandingkan dengan gigi yang pembentukan akarnya telah sempurna sebanyak $15 \% .{ }^{10}$ Komplikasi yang paling sering berhubungan dengan ototransplantasi gigi adalah ankilosis dan resorpsi akar. Banyak faktor yang memengaruhi hasil transplantasi, seperti umur pasien, tahap perkembangan akar gigi, trauma saat pembedahan, penggunaan splinting, jenis donor, ${ }^{13-14}$ durasi paparan ekstra oral gigi donor selama pembedahan, kerusakan pada sementum akar dan ligamen periodontal, dan pengalaman dari ahli bedah mulut itu sendiri. ${ }^{13}$

Suatu transplantasi dikatakan berhasil jika terdapat respon vitalitas yang positif, periodonsium normal, dan perkembangan akar yang normal; akar gigi mengisi daerah transplantasi, periodonsium normal, dan perkembangan akar yang normal; terdapat respon vitalitas yang positif, periodonsium normal, dan perkembangan akar yang terhenti. Sedangkan transplantasi dikatakan tidak berhasil jika gigi yang ditransplantasi tercabut. ${ }^{13}$

\section{Bone graft dan splitting osteotomy}

Bone graft terdiri dari autograft, jaringan tulang berasal dari individu yang sama; allograft, berasal dari individu yang berbeda; heterograft, berasal dari spesies yang berbeda; alloplastic graft, menggunakan tulang sintesis seperti hydroxylapatite, phosphoric calcium ceramics, dan oily calcium hydroxide dalam bentuk krim. ${ }^{15}$ Sejauh ini jenis graft yang paling sering digunakan adalah free autogenus bone graft. Ketika graft yang dilakukan berasal dari pasien yang sama, hal itu tidak mendatangkan respon penolakan dari sistem imun pasien. Graft ini biasanya diperoleh dari maksila, mandibula, kranium, dataran tinggi tibia, iliac crest, dan tulang rusuk. ${ }^{16}$

Bone graft merupakan tindakan yang cocok untuk menambah prosesus alveolar secara vertikal, pembentukan kembali tulang rahang, transfer jaringan yang bebas dari mikrovaskular, dan pembentukan kembali cleft alveolar. ${ }^{15}$

\section{Pemilihan bahan bone graft untuk alveolus}

Ketahanan jaringan yang akan didonor merupakan aspek penting dalam bone graft.
Dalam kondisi optimal, sel osteogenik akan mempertahakan prosedur pembedahan. Lilja $^{17}$ yang mengutip Johansen dan Rockert membuktikan melalui penelitian eksperimen dengan melakukan cancellous autogenus bone graft, pengambilan tulang dari tibia atau crest iliac yang kemudian dipindahkan ke jaringan yang memiliki struktur yang sama sebagai lempeng di sekitarnya. Setelah enam bulan dilakukan pemeriksaan secara mikroradiografik atau morfologik untuk membedakan sampel biopsi dari regio graft dalam sekali pengambilan lempeng yang normal pada usia yang sama. Lebih jauh lagi, arsitektur dari graft menunjukkan adaptasi terhadap keperluan fungsional.

\section{Tulang cansellous dan tulang kortikal}

Pembentukan tulang yang baru berawal pada permukaan trabekula yang ada. Tulang cansellous memiliki banyak vaskularisasi, lebih berongga, mengandung lebih banyak regenerasi tulang, memiliki pertumbuhan tulang baru yang lebih baik yang dimulai dari daerah tepi perbatasan graft dengan jaringan di sekitarnya. Pada prinsipnya, cansellous autograft mengalami penyembuhan secara osteogenesis, kemudian diikuti dengan resorbsi tulang trabekula yang banyak pada jaringan donor. ${ }^{17}$

Pembentukan nutrisi awal pada sel tulang kortikal memerlukan restorasi dari aliran pembuluh yang ada atau kanalikuli dan pertumbuhan kapiler. Suatu graft kortikal seringkali mengalami kematian dan diganti oleh invasi sel tulang yang berasal dari daerah resipien. Pergantian metabolik dan pembentukan kembali tulang kortikal seringkali lebih lama dibandingkan dengan tulang cansellous, pada kortikal graft juga tidak bisa dilakukan pembentukan kembali toothbearing function dari prosesus alveolar. ${ }^{17}$

\section{Splitting Osteotomy}

Splitting osteotomy merupakan salah satu tindakan bedah yang direkomendasikan pada transplantasi gigi ke daerah yang mengalami atrofi horisontal untuk memperoleh daerah resipien yang adekuat (gambar 4). ${ }^{1-2}$ Pada pelaksanaannya, splitting osteotomy prosesus alveolaris dilakukan dengan insisi mukosa, kemudian plat kortikal bukal dipotong dengan satu osteotomy sagital dan dua osteotomy vertikal lalu sebuah chisel dimasukkan ke dalam dan ditekan ke daerah bukal sehingga terbentuk celah untuk menempatkan gigi yang akan ditransplantasi. 

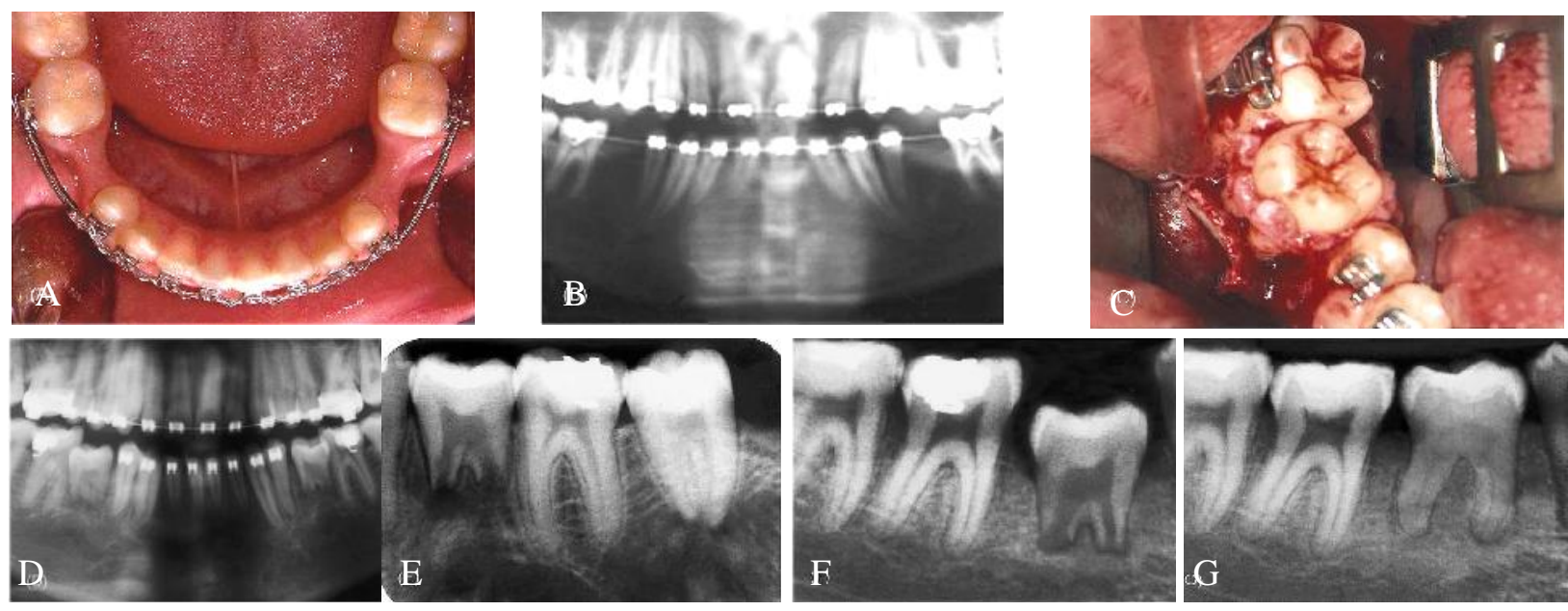

Gambar 4. Transplantasi bilateral gigi molar ketiga yang disertai splitting osteotomy prosesus alveolaris pada pasien laki-laki usia 17,5 tahun dengan aplasia gigi 35 dan 45. A. Keadaan klinis setelah pembukaan ruang secara ortodontik. Terdapat atrofi prosesus alveolaris yang ekstrim. B. Gambaran foto panoramik yang menunjukkan atrofi prosesus alveolaris. C. Kondisi intra operatif setelah dilakukan splitting osteotomy dan transplantasi molar ketiga ke ruang yang telah disediakan. D. Gambaran radiologi segera setelah dilakukan transplantasi. E. Gambaran radiologis intra oral transplantasi pada mandibula kiri menunjukkan tanda-tanda inflamasi resorpsi akar dan radiolusensi 3 bulan setelah transplantasi. F. Gambaran radiologi 3 bulan kemudian dari gigi yang ditransplantasi pada mandibula kanan dengan periodontal space yang normal. G. Gambaran radiologi dari transplantasi yang sama pada saat 5,2 tahun setelah transplantasi. Pertumbuhan akar terjadi secara sempurna dan terjadi kehilangan pulpa secara total. (Sumber: Bauss O, Engelke W, Fenske C, Schilke R, Schwestka-Polly R. Autotransplantation of immature third molars into edentulous and atrophied jaw sections. Int J Oral Maxillofac Surg 2004; 33: 558-63). ${ }^{2}$

\section{PEMBAHASAN}

Transplantasi gigi dapat menjadi pencetus terjadinya gangguan suplai vaskular ke pulpa. Banyak bukti menunjukkan bahwa setelah transplantasi, banyak gigi dengan pembentukan akar yang belum sempurna mengalami kematian jaringan pulpa. ${ }^{1}$ Revaskularisasi merupakan suatu proses terjadinya pertumbuhan yang tinggi dari vaskularisasi jaringan penghubung ke dalam ruang pulpa atau merupakan suatu keadaan pembuluh darah di dalam ruang pulpa gigi yang ditransplantasi telah terbentuk dan berhubungan dengan pembuluh darah dari jaringan periodonsium. ${ }^{18}$ Revaskularisasi dimulai pada hari keempat setelah operasi dan pertumbuhan ini akan terbentuk sempurna setelah 30 hari dengan seluruh pulpa yang berisi pembuluh-pembuluh baru. Tindakan transplantasi gigi yang belum terbentuk sempurna menunjukkan tindakan bedah pengangkatan pada waktu pembentukan akar belum sempurna. ${ }^{1}$ Perkembangan akar lebih lanjut setelah transplantasi bergantung pada koordinasi dari aktivitas pulpa dan Hertwig's epithelial root sheat (HERS) serta sel-sel ligamen periodontal. Pada kombinasi jaringan ini, HERS memiliki peranan yang paling besar. ${ }^{1,11,15}$ Sejumlah penelitian telah menunjukkan bahwa transplantasi gigi dapat menjadi pencetus terjadinya pengurangan panjang akar. ${ }^{1}$ Andreasen, dkk menghubungkan kejadian berkurangnya panjang akar dengan pemutusan parsial atau destruksi dari HERS selama prosedur transplantasi atau terhalangnya nutrisi sampai terjadinya revaskularisasi penuh dari gigi yang ditransplantasi. Hanya sebagian kecil faktor klinik yang ditemukan mempengaruhi HERS dan perkembangan akar gigi setelah transplantasi. Yang termasuk dalam hal ini adalah tahap perkembangan akar gigi, posisi ektopik graft sebelum transplantasi, fiksasi transplantasi dalam posisi erupsi, memperpanjang fiksasi rigid dari transplantasi, dan prosedur bedah yang luas seperti splitting osteotomy dari prosesus alveolar. ${ }^{5}$

Hanya sebagian kecil penelitian yang menguji pengaruh transplantasi terhadap panjang akhir akar gigi dan penambahan panjang akar gigi molar ketiga yang immature.

Nutrisi di daerah transplantasi bergantung pada penyebaran jaringan di sekitar daerah resipien sampai terjadinya revaskularisasi. Pada kasus transplantasi yang dikombinasi dengan free bone autograft, penyebaran suplai nutrisi meliputi gigi dan fragmen tulang yang ditransplantasi sehingga hal ini dapat menyebabkan kekurangan atau lambatnya penyebaran nutrisi pasca operasi pada permukaan akar gigi yang ditransplantasi. Keadaan ini menimbulkan anggapan bahwa aplikasi free bone autograft memiliki pengaruh 
negatif terhadap nutrisi HERS dan perkembangan akar pasca operasi. Namun demikian, dalam penelitian yang dilakukan Bauss, $\mathrm{dkk}^{1}$ tidak ditemukan pengaruh yang signifikan terhadap perkembangan akar gigi yang ditranplantasi. Hal ini berhubungan dengan jumlah dan aplikasi free bone autograft yang sangat dibatasi secara lokal, yaitu hanya meliputi $2 / 3$ akar bagian atas dari permukaan bukal sehingga memungkinkan terbawanya nutrisi ke daerah apikal dan HERS. ${ }^{1}$

Bauss $\mathrm{dkk}^{1}$ juga menjelaskan transplantasi yang dikombinasi bersama splitting osteotomy dari prosesus alveolaris menunjukkan ukuran panjang akar akhir dan penambahan panjang akar yang lebih rendah, terjadi pemutusan parsial dari HERS selama prosedur transplantasi dan terjadi kekurangan nutrisi pada HERS pasca operasi. Hal tersebut berhubungan dengan bentuk yang kurang menguntungkan dari daerah resipien. Setelah splitting osteotomy, daerah resipien seringkali lebih luas di daerah korona dan sempit ke arah apikal sehingga ujung akar sulit untuk berkontak dengan tulang selama mencobakan transplantasi pada soket resipien, dan berikutnya terjadi kerusakan HERS. Splitting osteotomy dari prosesus alveolaris dapat menimbulkan berkurangnya vaskularisasi dari daerah resipien. Hal ini dapat menyebabkan berkurangnya nutrisi dari HERS dan mengakibatkan pembatasan potensi pertumbuhan akar. Hubungan antara ketidakcukupan daerah resipien dan berkurangnya perkembangan akar pasca operasi didukung oleh temuan bahwa efek negatif dari splitting osteotomy tampak pada terbatasnya perkembangan akar pada tahap awal. Penelitian terdahulu menunjukkan kerentanan yang lebih besar dari transplantasi molar ketiga pada tahap perkembangan awal hingga nutrisi HERS yang terbatas setelah transplantasi. ${ }^{1-2}$

\section{SIMPULAN}

Tindakan free bone autograft tidak memberikan pengaruh yang signifikan terhadap perkembangan akar gigi yang ditransplantasi jika jumlah dan aplikasi free bone autograft dibatasi secara lokal. Free bone autograft yang digunakan hanya meliputi $2 / 3$ akar bagian atas dari permukaan bukal sehingga memungkinkan terbawanya nutrisi ke daerah apikal dan HERS. Tindakan splitting osteotomy dapat memberikan pengaruh negatif terhadap pulpa dan kondisi jaringan periodontal gigi molar ketiga immature yang ditransplantasi dan dapat menyebabkan gangguan revaskulariasi pulpa yang disebabkan oleh tidak adekuatnya nutrisi pada daerah resipien.

\section{SARAN}

Ukuran graft pada transplantasi yang dilakukan bersama bone graft di daerah yang mengalami atrofi vertikal, disarankan hanya pada 2/3 bagian atas akar sehingga suplai nutrisi dapat mencapai daerah apikal dan HERS. Sedangkan pada daerah resipien yang mengalami atrofi horisontal dapat digunakan splitting osteotomy, meskipun teknik ini perlu dipertimbangkan karena dapat berpengaruh negatif terhadap pulpa dan jaringan periodontal gigi yang ditransplantasi.

\section{DAFTAR PUSTAKA}

1. Bauss O, Zonios I, Engelke W. Effect of additional surgical prosedures on root development of transplanted immature third molar. Int $\mathbf{J}$ Oral Maxillofac Surg 2008; 37: 730-5.

2. Bauss O, Engelke W, Fenske C, Schilke R, Schwestka-Polly R. Autotransplantation of immature third molars into edentulous and atrophied jaw sections. Int J Oral Maxillofac Surg 2004; 33: 558-63.

3. Morfologi gigi desidui dan gigi permanen. [online] 2009 [cited 2009 December 19]. Available from URL:http://usupress.usu.ac.id/files/morfologigigide cidui\&permanen_final_normal_awal.pdf

4. Mathew BP, Hegde MN. Management of non vital immature teeth. Endodontology. [online] 2009 [cited 2009 December 19]. Available rom URL: http://medind.nic.in/eaa/t06/i1/eaat06i1p18.pdf.

5. Andreasen JO, Paulsen HU, Yu Z, Bayer T. A longterm study of 370 autotransplanted premolars. Part IV.Root development subsequent to transplantation. Eur J Orthod 1990: 12: 38-50.

6. Mansjoer A, Triyanti K, Savitri R, Wardhani WI, Setiowulan W. Kapita selekta kedokteran. Edisi ketiga. Jakarta: Media Aesculapius; 2000.

7. Sunil CK, Mohan B, Lakshminrayanan L. Autogenous tooth transplantation-two clinical case. Endodontol 2001; 13:51-6.

8. Tanne K. Tooth transplantation: the current status and the future development with a cryopreservation technique for teeth banking.The Medical Equipment Seminar between Switzerland and Japan; 2006 Nov 14; Zurich, Switzerland. Medical and Social Cooperating Center Graduate School of Biomedical Sciences Hiroshima University; 2006. p. 3-4.

9. Dorland's illustrated medical dictionary. $29^{\text {th }}$ ed. Philadelphia: W.B. Saunders; 2002. Tooth t; p. 2275.

10. Mendes RA, Rocha G. Mandibular third molar autotransplantation-literature review with clinical case. J Can Dent Assoc 2004; 70(11):761-6. 
11. Thomas S, Turner SR, Sandy JR. Autotransplantation of teeth: is there a role? $\mathrm{Br} \mathrm{J}$ Orthod 1998; 25:275-82.

12. Nethander G, Skoglund A, Kahnberg KE. Eksperimental autogenous tooth transplantation in the dog: a comparison between one- and two-stage surgical techniques. Acta Odontol Scand 2003; 61:223-9.

13. Kvinta S, Lindstenb R, Magnussonc A, Nilssond P, Bjerkline K. Auto transplantation of teeth in 215 patients, a follow up study. Angle orthod 2010; 80:446-50.

14. Hernandez SL, Carnero RC. Autogenic tooth transplantation: a report of ten cases. J Oral Maxillofac Surg 1986; 46: 1051-5.
15. Fragiskos FD. Oral surgery. NewYork: SpringerVerlag Berlin Heidelberg; 2007. p.70.

16. Miloro M, Ghali GE, Larsen PE, Waite PD. Peterson's principal of oral and maxillofacial surgery. $2^{\text {nd }}$ ed. Toronto: BC Decker Inc; 2004. p. 165 .

17. Lilja Jan. Alveolar bone grafting. Indian J Plast Surg 2009; 42:110-5.

18. Siers ML, Willemsen WL, Gulabivala K. Monitoring pulp vitality after transplantation of teeth with mature roots, Introduction-case report. [online] 2010 [cited 2010 January 29]. Available from URL: http://endodonticsjournal.com/articles/ 35/1/Monitoring-pulp-vitality-after-transplantationof-teeth-with-mature-roots/Page1.html. 